\title{
MANAGING THE ENVIRONMENTAL ADAPTATION OF VEHICLE OPERATIONS
}

\author{
ALLA GOLUBEVA ${ }^{1}$, ELENA MAGARIL ${ }^{1}$, ROMEN MAGARIL ${ }^{2}$, \\ DEBORAH PANEPINTO ${ }^{3}$ \& FRANCESCA VIGGIANO ${ }^{4}$ \\ ${ }^{1}$ Department of Environmental Economics, Ural Federal University, Russian Federation \\ ${ }^{2}$ Department of Oil and Gas Processing Technology, Tyumen Industrial University, Russian Federation \\ ${ }^{3}$ Department of Environment, Land and Infrastructure Engineering, Politecnico di Torino, Italy \\ ${ }^{4}$ European Organization for Nuclear Research, CERN, Geneva, Switzerland
}

\begin{abstract}
The growing vehicle fleet, which is the largest consumer of the hydrocarbon fuels and the emitter of toxic substances and greenhouse gases, creates the serious environmental challenges that require an integrated approach to solve them. Simulation of the alternative scenarios for the traffic flows distribution allows evaluating the impact of various schemes of the road traffic organization and changes of the road infrastructure on the state of atmospheric air. It is necessary to consolidate the application of the legislative, economic and management mechanisms, orienting parties responsible for the negative consequences of the car operation to implement the optimal technological solutions. Possible economic incentives for the manufacturers of the vehicles, fuel producers, and the car owners are discussed, which enable to improve the environmental safety of the motor vehicles operation. The proposed model of an environmental fuel tax has been tested in the evaluating of the annual value of the possible additional tax revenues from a number of Russian refineries. The introduction of the proposed tax model can significantly reduce the negative consequences of vehicles operation.

Keywords: vehicle, traffic flows, environmental fuel tax, technological solutions, vehicles operation, greenhouse gases, economic mechanism.
\end{abstract}

\section{INTRODUCTION}

The continuous growth of the world vehicle fleet, already exceeding one billion units, entails an intensification of the hydrocarbon fuels consumption. Fig. 1 compares the contribution of the transport to the global energy consumption with the other sectors, Fig. 2 shows the contribution of the transport to the petroleum products consumption dynamics. The increase in the energy consumption by the transport is accompanied by an increase in the fuel combustion products emission into the atmosphere, causing both local and global changes in the state of the natural environment and creating environmental and climatic hazards that require a serious approach to the problem solution. Fig. 3 shows the contribution of the transport to the global emission of carbon dioxide. It should be noted that although the considerable attention has been paid to the introduction of the alternative types of energy and fuel, by the current moment their use by the world vehicle fleet is not significant. It is necessary to ensure the positive dynamics of the environmental safety of the transport operation using legislative, economic and management mechanisms that optimize the technological and organizational measures for increasing the energy efficiency and reducing the negative environmental consequences. While elaborating the urban areas development strategy it is also important to simulate the different scenarios for the traffic flows distribution and the corresponding change in the atmospheric air quality.

\section{MODELLING APPROACH TO MOBILITY AND TRAFFIC DISTRIBUTION}

One potential meaningful instrument that can be used in order to limit the deleterious impact of the automotive transport on the air quality of the metropolitan areas is the identification 


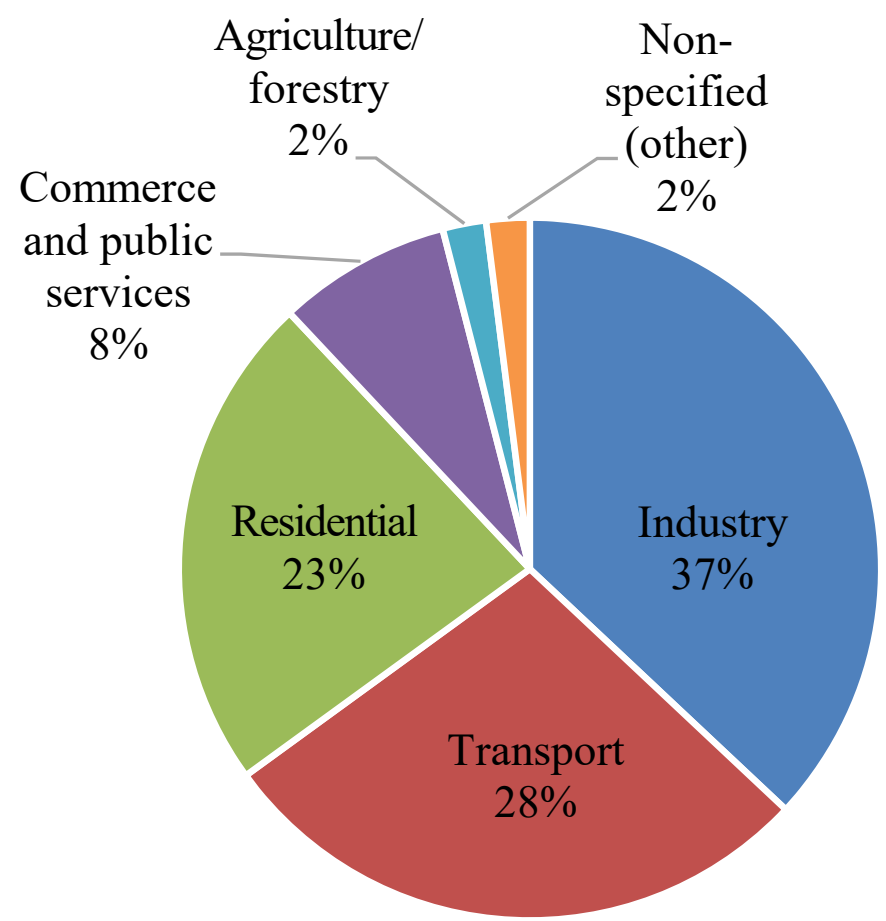

Figure 1: Energy total final consumption by sectors in 2014 (according to [1]).

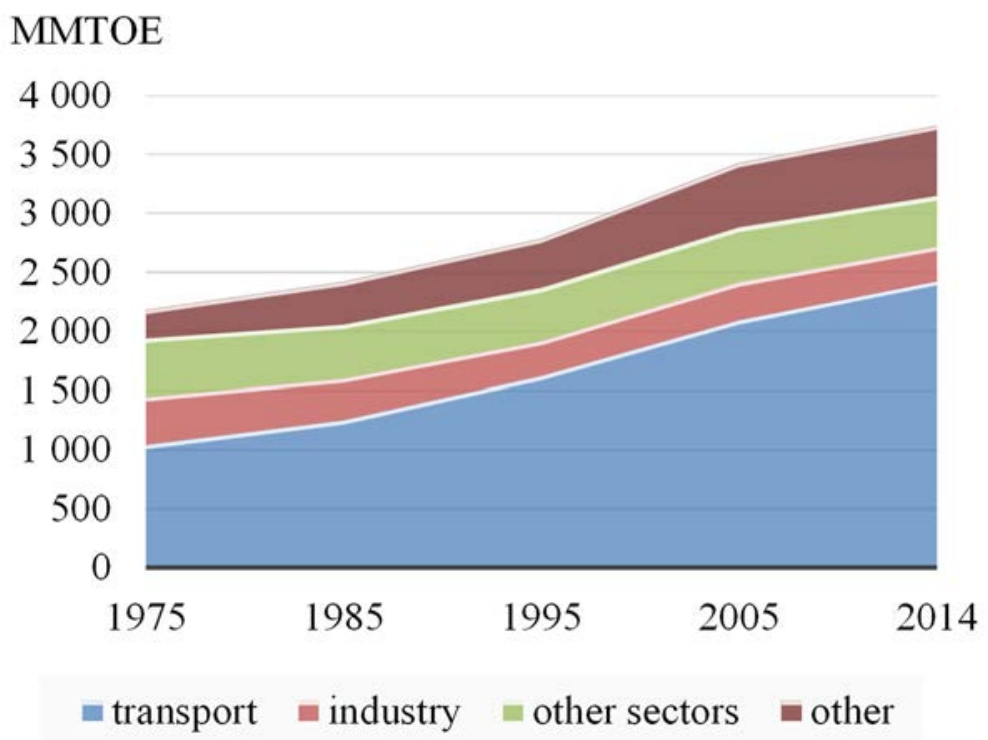

Figure 2: The petroleum products consumption in the world by the sectors (according to [2]). 


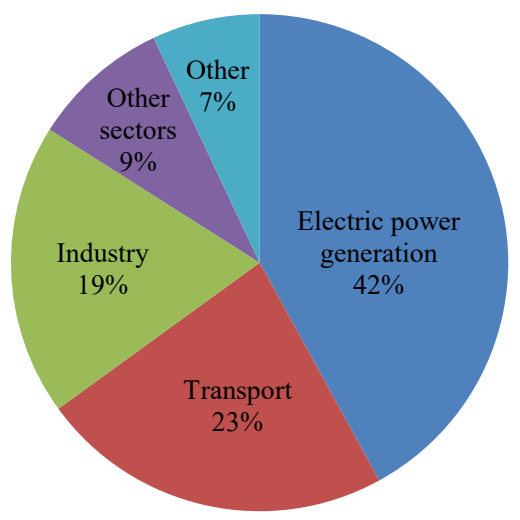

Figure 3: The structure of $\mathrm{CO}_{2}$ emission from the fuel combustion in the world by the sectors (according to [3]).

and the following implementation of the optimal traffic networks by evaluating the effect of different traffic schemes regarding the concentration of the most critical air pollutants.

The following steps for this approach are required:

- Determination of the different traffic scenarios established on the basis of the realization of the road infrastructure, implementation and stimulation of the public transport usage, limitation of the traffic in the most critical hours of the day and in the most critical areas. While determining these scenarios it is necessary to take into account the potentialities of the public authority's regulations, the cost of the new infrastructure realization, the possibility to use economic tools to motivate or demotivate some traffic choices;

- Evaluation of the traffic flows resulting from the choice of a specific traffic scenario: the largely used traffic models, that are well consolidated in the practice of the city planners, can be utilized on the basis of the traffic needs and the consequent determination of the road and public transport infrastructures, to determine the potential future traffic flows;

- By using well known and consolidated emission factors for the different operating transport vehicles, it is possible to associate the potential maps of the emission distribution in the considered scenarios with the traffic flows determined as indicated in the previous point; the comparison of the emission distribution in the evaluated present and future scenarios leads to a first indication of the benefits of the established choice in terms of planning sustainability;

- Creation and evaluation of an atmospheric transport, dispersion and transformation model, which enables to establish the correlation between emissive fluxes of the principal pollutants and the air quality in the considered area on the basis of meteorology, atmospheric chemical kinetics, and topography of the area. Many complex models have been created and implemented for the evaluation of the dispersion from a linear emission area (like a road), and in particular the models of the Caline series defined by the California air quality authorities, they are highly effective for this purpose. It is important to carefully consider the complexity of this step from the point of view of data collection, model implementation, sources 
definition, but it seems to be a fundamental step in order to arrive to a useful concrete final result;

- Use of the validated atmospheric model to determine the pollutants concentration distribution (air quality) in the considered area and for the hypothesized scenarios with the final result to establish the comparative benefits of the proposed scenarios. This comparison is done on the basis of the real determined impact, evaluated not in terms of the potentiality (emission scenarios) but in terms of the real effect on the population and biosphere based on the local air quality determination.

The final results consist in the determination of the emissive flows and the modified air quality with the aim to compare different traffic scenarios. The comparison of the scenarios results can become a very important tool for the urban planners and to define the future strategies of the city development.

As an example, Fig. 4 shows two simulated maps of PM2.5 concentration in the United States, with and without adoption of the procedures established by the Clean Air Act (Clean Air Act Amendments (CAAA))).

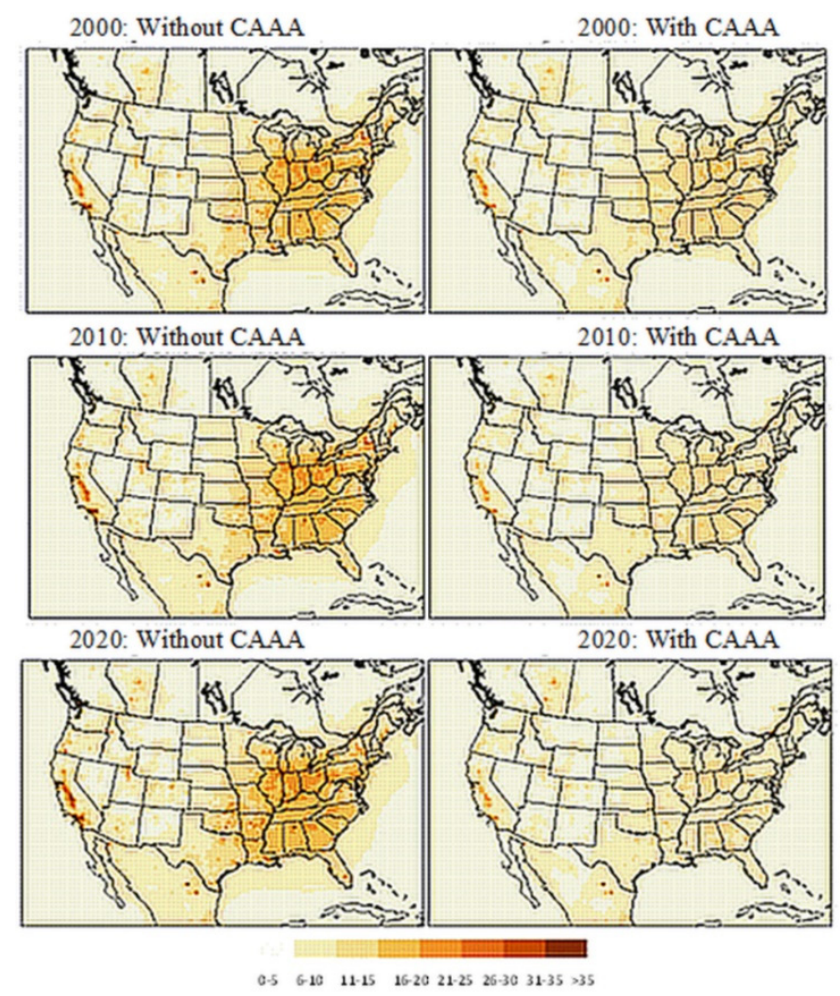

Figure 4: Simulated maps of annual average PM2,5 species concentration $\left(\mu \mathrm{g} / \mathrm{m}^{3}\right)$ across the 36-km continental U.S. modeling domain for the period from 1990 to 2020 (according to [4]). 
Such a tool based on modelling prevision must be evaluated in the combination with the other intervention possibilities (new fuels, engines improvement, different movement requirements), and it must be coordinated with them: a real, effective strategy is composed from the use of the best environmentally acceptable cars and their distribution in the areas less susceptible to the atmospheric pollution: a direct benefit from this strategy practical introduction is the air quality.

\section{THE STIMULATION OF THE INCREASE IN THE ENVIRONMENTAL SAFETY OF THE VEHICLES OPERATION}

The growth of the transport sector on a global and national scale happens mainly due to the motor transport, and first of all due to the passenger cars in personal property. According to the IEA [5], motor transport makes a determining contribution into the fuel consumption structure and, accordingly, into the carbon dioxide emission by the transport sector. It should be noted that carbon dioxide emission during fuel combustion correlates with toxic substances emission as a whole and thus is an indicator of the total negative load on the environment from the transport operation [6]. Consequently, the motor transport is the main contributor to the negative environmental impacts of the transport sector. Fig. 5 shows the dynamics of the vehicles number in Russia.

When choosing the measures to improve the environmental adaptation of motor vehicles, it is necessary to take into account not only the technological aspects, but also the possible changes in the way of life, the surpassed development of the public transport relative to the personal transport. The replacement of the existing fleet of the old cars with new ones, which have the improved fuel efficiency and lower specific emission of the toxic substances and greenhouse gases, should be initiated at the state level.

The main parties responsible for the environmental safety of the vehicles operation are vehicles manufacturers, the motor fuel producers and the car owners. Accordingly, various incentive measures are applied to them, using the state support, tax, and financial and credit instruments, as well as flexible pricing policies and an environmental certification system.

\section{Mln.Units}

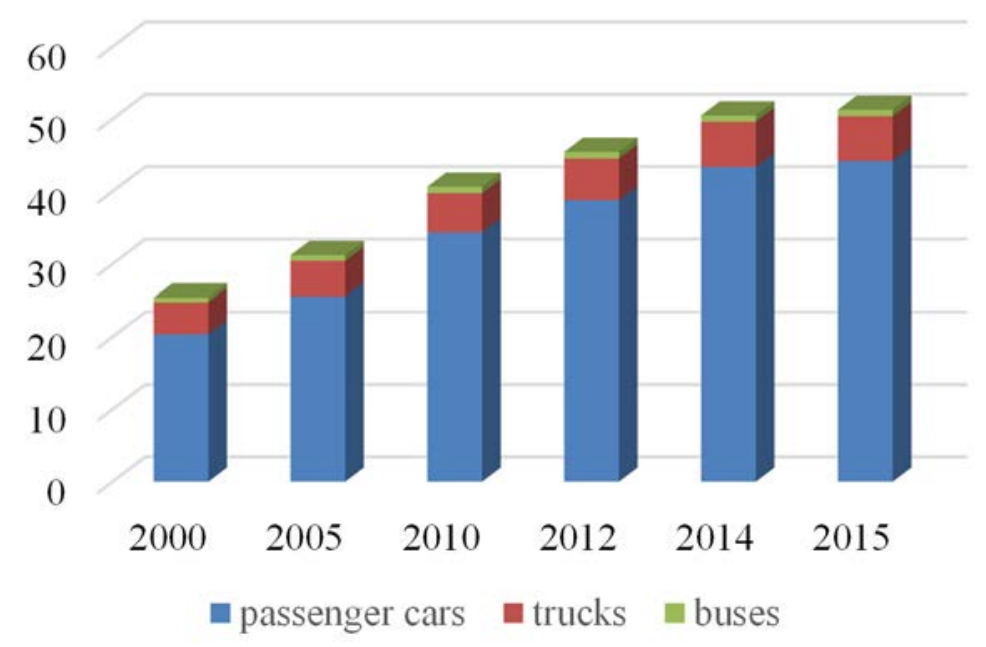

Figure 5: The dynamics of the vehicles number in Russia [7]. 
Among the measures of the economic incentives for the vehicles owners (both auto enterprises and private individuals) that ensure the compliance with the principles of the economic driving, one can note the state support of the development and introduction of the new technologies for the application of the smart transport systems, the construction of the road network and the transport systems reconstruction. The system of penalties for the untimely maintenance and repairs, the progressive tax on the car owners depending on the period of use of their cars contribute to the observance of the car operation rules. Such methods as the preferential prices for the cars with high fuel efficiency, including those using the alternative fuels and energy, preferential taxes for the auto companies with a high share of such models in their stock, programs for the recycling of the old cars will contribute to a structural shift in the vehicle fleet in favor of the fuel-efficient models.

Stimulating measures for the manufacturers of the transport equipment include the preferential loans, as well as the provision of the environmental subsidies for the development of the technologies to improve the engines and cars design, including the transfer of the vehicles to the alternative fuels and energy.

It should be noted that the quality of the produced fuels is a limiting factor in ensuring the vehicles environmental safety - all other things being equal. When using the low-quality fuel it is impossible to achieve a positive dynamics in the environmental safety of the cars operation by other methods, including the improvement of the construction parameters, road infrastructure, traffic control systems, etc. Therefore, the incentive measures aimed at the fuel producers are particularly significant. Such measures can be presented by the state support for the oil-refining industry modernization, the development and production of the alternative fuels, as well as the concessional lending for the new refineries construction, the development and production of the alternative fuels, and investment subventions. Considering that the fuel of the higher environmental class is sold at a higher price, which is a demotivating factor for the consumers, a government restriction on the growth of the motor fuel prices and the provision of the tax subsidies to the producers of the fuel of environmental friendly quality may be a useful measure. It is also necessary to support the developers and manufacturers of the fuel additives that reduce the specific fuel consumption, and to introduce the mandatory use of the additives in standards and technical regulations, as the use of the highly effective additives is a very successful method for increasing the energy efficiency and the motor vehicles environmental safety [8]-[11]. Considering that both the fuel consumption and the emission of both the polluting toxic substances and greenhouse gases increase with the content of the aromatic hydrocarbons in the fuel [12] and, accordingly, with the fuel density increasing [13], it is advisable to introduce the density index into the quality certificates of the produced fuel.

Fiscal regulation of the oil and gas complex ensures a steady increase in budget revenues and stimulates the attraction of the investments and modern technologies of the world level. The tax mechanisms contribute to the economic development of the oil and gas complex and can become a factor of the sustainable development of the motor transport [14], [15].

Taking into account the correlation of specific indicators of the carbon dioxide emission, the fuel consumption and emission of the toxic substances by the transport, earlier the authors proposed the following model of the environmental fuel tax [16]:

$$
T_{e n v_{i j}}=R_{i j} \cdot G_{i j}=\left(R_{b}+R_{a d}\right) \cdot G_{i j}
$$

where $T_{e n v_{i j}}$ is an environmental tax value on the $i$ fuel type of the $j$ environmental class, monetary units; $R_{i j}$ is a motor fuels environmental tax rate, monetary units / ton of fuel; $G_{\mathrm{ij}}$ is a weight of the 
sold $i$ fuel type of the $j$ environmental class, tons; $R_{b}$ is a basic environmental tax rate on the $i$ fuel type of the $j$ ecological class, monetary units / ton, established for a given fuel environmental class; $R_{a d}$ is an additional rate of the environmental tax on the $i$ fuel type, monetary units/ton, determined depending on the amount of $\mathrm{CO}_{2}$ emission from the fuel combustion related by the linear correlation with the fuel density.

This approach was used by the authors to estimate the annual value of the additional tax revenues provided that the proposed environmental tax is introduced relative to the current excise taxes for certain refineries in Russia, Table 1.

Table 1: The annual additional value (relative to the current excise taxes) of the proposed environmental tax on motor fuels.

\begin{tabular}{|c|c|c|c|c|}
\hline \multirow[t]{2}{*}{ Refinery } & \multirow{2}{*}{$\begin{array}{c}\text { Productive } \\
\text { capacity } \\
\text { oil processing } \\
\text { volume), } \\
\text { mln.tons }\end{array}$} & \multicolumn{2}{|c|}{$\begin{array}{c}\text { Production } \\
\text { volume in } 2015, \\
\text { mln.tons }\end{array}$} & \multirow{2}{*}{$\begin{array}{l}\text { The amount of the } \\
\text { environmental tax due } \\
\text { to the additional rate } \\
\text { proportional to the } \\
\text { fuels density, mln. } \\
\text { rubles }\end{array}$} \\
\hline & & Gasoline & $\begin{array}{c}\text { Diesel } \\
\text { oil }\end{array}$ & \\
\hline \multicolumn{5}{|c|}{ ROSNEFT $^{\mathrm{a}}$} \\
\hline JSC «Ryazanskayaoil refining company» & 18.8 & 2.9 & 4.0 & 130.8 \\
\hline LLC «RN-Tuapsinsky refinery» & 12.0 & 0 & 3.1 & 84.6 \\
\hline JSC «Angarskayapetrochemicalcompany» & 10.2 & 1.3 & 3.0 & 91.6 \\
\hline JSC «Novokuibyshevsky refinery » & 8.8 & 1.3 & 2.6 & 80.7 \\
\hline JSC «Syzransky refinery » & 8.5 & 1.1 & 2.3 & 71.0 \\
\hline LLC «RN-Komsomolsky refinery » & 8.0 & 0.4 & 2.5 & 71.2 \\
\hline JSC «Achinsky refinery VNK» & 7.5 & 1.0 & 2.1 & 64.8 \\
\hline JSC «Kuibyshevsky refinery » & 6.8 & 0.9 & 2.1 & 64.0 \\
\hline PJSC «Saratovsky refinery » & 7.0 & 1.0 & 1.7 & 53.9 \\
\hline \multicolumn{5}{|c|}{ LUKOIL $^{\mathrm{b}}$} \\
\hline $\begin{array}{l}\text { LLC’LUKOIL- } \\
\text { Nizhegorodnefteorgsintez" }\end{array}$ & 17.0 & 4.0 & 5.0 & 165.6 \\
\hline LLC'LUKOIL-Permnefteorgsintez" & 13.1 & 2.0 & 4.6 & 140.7 \\
\hline $\begin{array}{l}\text { LLC2 “LUKOIL - } \\
\text { Volgogradneftepererabotka»" }\end{array}$ & 15.7 & 2.3 & 5.2 & 158.7 \\
\hline LLC «LUKOIL-UNP» & 4.0 & 0.6 & 1.0 & 30.4 \\
\hline \multicolumn{5}{|c|}{ GAZPROMNEFT $^{c}$} \\
\hline Omskyrefinery & 20.9 & 4.4 & 6.3 & 204.3 \\
\hline Moscowrefinery & 11.0 & 2.7 & 2.1 & 77.2 \\
\hline Processing complexNIS & 2.9 & 0.5 & 1.3 & 38.0 \\
\hline \multicolumn{5}{|c|}{ SURGUT-NEFTEGAS $^{\mathrm{d}}$} \\
\hline LLC "KINEF" & 20.5 & 2.5 & 6.4 & 193.3 \\
\hline
\end{tabular}

${ }^{a}$ According to the annual report of JSC "NK ROSNEFT" of 2015, available at

https://www.rosneft.ru/Investors/statements_and_presentations/annual_reports/

${ }^{\mathrm{b}}$ According to the report for the investors of LUKOIL, available at

http://www.lukoil.ru/InvestorAndShareholderCenter/IrTool/InteractiveAnalysis/interactive-analysis-

neww8?wid=wid4dcOqUyoa0OihSw0u4ieug

'According to the annual report of GAZPROMNEFT of 2015, available at http://ir.gazprom-neft.ru

${ }^{\mathrm{d} A c c o r d i n g}$ to the annual report of SURGUT-NEFTEGAS of 2015, available at

http://www.surgutneftegas.ru/investors/reports/annual/ 
On the scale of Russia, with the existing volumes of gasoline and diesel fuel production [17], the replacement of the current excise taxes by the environmental tax can lead to the increase in the tax revenues to the budget, estimated as up to 2.4 billion rubles per year. Due to these additional funds, a road fund can be formed to finance the rehabilitation of road surfaces; some of the funds can be used to implement environmental protection measures. The proportion of the funds from the payment of the proposed tax allocation should be determined individually, taking into account the features of the region in question (the region, where fuel is sold in this period). When switching to the production of the motor fuels with a minimum density within the given environmental class, the motor fuels consumption and emission of the toxic substances and greenhouse gases during the motor vehicles operation will significantly decrease.

\section{CONCLUSIONS}

The flow of the pollutants into the environment during the vehicles operation is associated, on the one hand, with the technological aspects determining the specific emission and fuel consumption, and, on the other hand, with the traffic distribution and characteristics of the vehicle fleet that are largely determined by the political decisions and socio-economic factors. The impact of the different traffic distribution schemes on the air quality can be determined using the well-consolidated model approaches, which allows making strategically important decisions in the planning of urban infrastructure development. On the other hand, it should be noted that the formation of the secondary pollutants is difficult to predict due to the complexity of the corresponding kinetic dependencies.

It is necessary at the state level to stimulate the environmental solutions aimed at reducing the negative consequences of the motor vehicles operation, using the economic and management levers to influence the parties responsible for the emerging externalities. The tax instruments are very promising in this respect. The proposed model of the environment fuel tax can be effectively used in the conditions of the different states for more objective stimulation of the environmental characteristics improvement of the produced oil products. This will ultimately improve the environmental safety of the vehicles operation and their fuel efficiency. This approach can also be used at the interstate level, similar to the mechanisms of the Kyoto Protocol.

\section{ACKNOWLEDGEMENT}

The work was supported by the Act 211 of the Russian Federation Government, contract № 02.A03.21.0006.

\section{REFERENCES}

[1] Key World Energy Trends. Excerpt from World Energy Balances IEA 2016, http://www.iea.org/statistics/topics/energybalances/.

[2] World Energy Balances 2016 IEA Paris.

[3] $\mathrm{CO}_{2}$ Emission from Fuel Combustion 2016 OECD/IEA Paris, https://www.iea.org/publications/freepublications/publication/CO2EmissionsfromFu elCombustion_Highlights_2016.pdf.

[4] The Benefits and Costs of the Clean Air Act from 1990 to 2020 Final Report - Rev.A U.S Environmental Protection Agency Office of Air and Radiation April 2011, https://www.epa.gov/sites/production/files/2015-07/documents/fullreport_rev_a.pdf.

[5] Transport, Energy and CO2: Moving toward Sustainability2009 IEA, https://www.iea.org/publications/freepublications/publication/transport2009.pdf. 
[6] Golubeva, A. \& Magaril, E., Improved economic stimulation mechanism to reduce vehicle CO2 emission, WIT Transactions on the Built Environment, 130, pp. 437-445, 2013.

[7] Structure and forecast of the fleet of commercial vehicles in Russia 2016, https://www.autostat.ru.

[8] Bennett, J., Advanced fuel additives for modern internal combustion engines In: Folkson, R. (ed.), Alternative fuels and advanced vehicle technologies for improved environmental performance. Towards zero carbon transportation UK: Woodhead Publishing Ltd, pp. 165-194, 2014.

[9] Danilov, A.M., Development and use of fuel additives during 2006-2010 Chem tech fuels oil, 47(6), pp. 470-484, 2012.

[10] Magaril, E. \& Magaril, R., Improving the environmental and performance characteristics of vehicles by introducing the surfactant additive into gasoline. Environmental Science and Pollution Research, 23(17), pp. 17049-17057, 2016.

[11] Srivastava, S.P and Hancsók, J., Fuels and fuel-additives Hoboken New Jersey: John Wiley \& Sons Inc, 2014.

[12] Magaril, E. \& Magaril, R., Fuel quality: challenges to the sustainable development of automobile transport and approach to solution E3S Web of Conferences 6 03001, 2016.

[13] Magaril, E., Improvement of the environmental and operational characteristics of vehicles through decreasing the motor fuel density, Environmental Science and Pollution Research, 23(7), pp. 6793-6802, 2016.

[14] Mayburov, I. \& Leontyeva, Y., Transport tax in Russia as a promising tool for the reduction of airborne emission and the development of the road network. WIT Transactions on Ecology and the Environment, 198, pp. 391-401, 2015.

[15] Mayburov, I. \& Leontyeva, Y., Reducing the negative impact of motor transport on the environment: Prospects for the use of fiscal instruments in Russia. WIT Transactions on Ecology and the Environment, 186, pp. 863-874, 2014.

[16] Golubeva, A. \& Magaril, E., Environmental tax as an instrument of economic stimulation to improve the quality of motor fuels. WIT Transactions and The Environment, 192, pp. 149-159, 2015.

[17] Technological development of economic sectors in Russia, http://www.gks.ru/ wps/wcm/connect/rosstat_main/rosstat/ru/statistics/economydevelopment/\#. 